\title{
A instalação de hidrelétricas no Vale do Rio Uruguai e a constituição de um campo social de conflitos
}

\author{
Maria José Reıs \\ Unıversıdade do Vale do Itajaı Itajaı Brasıl \\ masereıs@hotmal com
}




\section{Resumo}

O objetivo deste texto e reconstituir a trajetoria histonca do Movimento dos Atıngidos por Barragens (MAB) uniciado no final da decada de 1970 na região do Alto Urugual (SC/RS) e que continua ate os dias atuals assumindo dımensão nacional e internacional Seu foco central e o campo social de conflitos que se iniciou quando se tornou publıca a instalação de hidreletricas na Bacia do Rio Urugual (SC/RS) por parte das Centrals Eletricas do Sul do Brasl (Eletrosul) Na reconstıtuıção da trajetoria hıstonica do referido campo de conflitos alem da atuação dessa empresa destaca se de modo especial a dos atingidos - em sua maioria agricultores famliares a serem removidos de seus territorios tradicionais - e a de seus mediadores - responsaveis iniciass pela organızação do $M A B$ - focalızando se sua organızaçao estrategıas de luta e conquistas

Palavras-chave hidreletricas migração compulsoria campo social de conflitos
Abstract

The purpose of this text is to trace the historical trajectory of the Movement of those Affected by Dams (Movimento dos Atingidos por Barragens MAB) which began at the end of the decade of $1970 \mathrm{in}$ the region known as Upper Uruguay (SC/RS) and continues up to the present to assume national and international dimensions Its main focus is the social field of conflict which began with the public announcement of the installation of hydroelectric dams on Uruguay River Basin (SC / RS) by the Centrats Eletricas do SUl do Brastl (ELETROSUL) In the reconstitution of the historical trajectory of the conflict this paper extends beyond the actoons of this company to highlight in a special way those who have been affected - mostly the familtes to be removed from their traditional territoriss - and thetr mediators - those responstble for the organization of the Movement - with focus upon theit organization strategies and achevements

Keywords hydroelectric dams compulsory migration soctal field of conflicts 


\section{Introdução}

aceleração de processos de desenvolvımento, no Brasıl, na segun-
da metade do século XX, caracterızou-se, dentre outros aspectos, pela unstalação de "projetos de grande escala" (Rubeiro, 1991), voltados para a disponıbılıdade de infraestrutura, entre os quais barragens destınadas a produção de energıa eletrıca Pesquisas nacıonaıs e internacıonaıs ${ }^{1}$ têm demonstrado que a unstalação destas obras desencadeıa processos socioambientais de extrema complexidade, compreendendo tanto aspectos tecnicos quanto sociais e politicos

Dentre seus multıplos desdobramentos, a instalação das hidreletricas requer uma reordenação territorial local Como parte dessa reordenação ha a necessıdade de deslocamento compulsorıo das populações locais, uma vez que seus espaços tradıcıonalmente ocupados serão convertıdos em reservatorıos ou lagos artıfıcıaıs, alem da aproprıação de seu entorno para dıferentes atıvıdades necessarıas ao funcionamento dos novos empreendimentos (Reis, Bloemer, 2001)

Movimentos sociaıs de resıstêncıa à unstalação dessas obras têm sido registrados nos mais diferentes contextos nacionaıs e internacionais, formando verdaderras redes de atores sociars mobılizados em torno deste problema Trata-se, a nigor, da constıtuıção de um “campo social de conflito (Swartz, 1968, Bourdieu, 1981), reunındo um conjunto de atores estruturalmente diferenciados, relacionados em um jogo de mútuas interações e confrontos, em um contexto sociopolítico específico

Este é o caso da instalação de 25 hidreletricas (UHEs), no vale do Rıo Uruguaı (SC/RS), pelas Centrais Elétrıcas do Sul do Brasıl (Eletrosul), cuja proposta ficou popularmente conhecida como "Projeto Uruguaı" A forte reação de uma parcela sıgnificatıva dos futuros 
"atıngıdos"2 pelo projeto se antecıpou, ao contrárıo da hidrelétrıca bınacional de Itaıpu, em relação ao inıcıo das obras Com sua mobılızação e organızação constıtuíram o 'Movımento dos Atıngıdos por Barragens" (MAB), que logrou ganhos significatıvos, sobretudo nas formas de compensação pelo deslocamento compulsorıo ao qual serıam submetıdos, e quanto ao adıamento temporano ou definıtıvo de algumas das obras a serem unstaladas na região

Este texto tem como objetıvo a reconstıtuıção da trajetóna do MAB, que será focalızado em relação a sua organızação e as suas estrategias de luta e conquistas, sendo destacadas a atuação da Eletrosul, dos futuros atıngıdos e de seus meduadores

\section{A atuação do setor elétrico}

O planejamento e as inıciatıvas da Eletrosul em relação ao aproveitamento hidroenergetico da bacıa do Uruguaı foram marcados pelas característıcas básıcas que norteavam o setor elétrıco brasıleıro desde a criação da Eletrobras, no inícıo da década de 1960 Ou seja, a exıstência, desde então, de um portentoso aparelho de planejamento, controle e gestão dos sıstemas de produção e dıstrıbuıção de energıa elétrica no conjunto do territonio nacional (Vaıner, Araújo, 1990, p 19) e a opção preferencial por grandes usinas de aproveitamento hidrico para o atendimento à demanda de eletricidade

De acordo com Vainer e Araújo (1990, p 20), em relação as providências relatıvas à desapropnação e ao deslocamento das populações ocupantes das áreas destınadas à implantação das hidreletricas, as subsıdiárıas das Centrais Elétricas do Brasll (Eletrobras) atuavam de modo semelhante, através de três estratégıas básıcas a desınformação, a perspectıva territonal patrumonualısta e a negocıação ındıvıdual

A desunformação, uma das prnncıpais estratégıas das empresas do setor elétrico em seu relacionamento com as referıdas populações, assumıa, nos momentos inıcıaıs de sua atuação em uma determinada região, como lembram os referıdos autores (1990, p 20), a forma pura e simples da sonegação de informações Essa sonegação possibilıtava o ingresso e a curculação de pessoal da empresa na região e faclitava a conquista de algumas posıções no espaço regıonal, antes que a população percebesse efetıvamente o que estava para acontecer Esta estratégı 

contınuava, por vezes, apos o inıcio das obras, através de uma especie de "propaganda enganosa", veıculada pelo próprio setor, que divulgava o empreendumento e seus supostos "beneficios' calando-se quanto aos aspectos socioambientais negativos Podıa, ıgualmente, ocorrer por meı da dıvulgação de unformações contraditónas ou desencontradas sobre varıos aspectos do andamento das obras, entre as quaıs as soluções relatıvas ao deslocamento das populações locais Gerar insegurança e duvidas faculıtava aos empreendedores a imposição de determinadas soluções à revelıa dos segmentos sociais potencialmente afetados pelos projetos

A estratégıa territorıal patrimonialısta, por sua vez, de acordo com Vauner e Araújo (1990, p 21) fol frequentemente utılızada pelo setor elétrıco quando se tratava de "crıar o vazıo demografıco necessarıo a instalação das barragens [ ]" Eram realizados cadastramentos socıoeconômicos fornecendo informações sobre cada estabelecumento rural ou urbano e seus respectıvos proprietarıos Estes dados norteavam, por melo da compra, a "desocupação" da area e sua reaproprıação por parte do setor elétrico, desconsiderando-se os direitos dos demais ocupantes da area, não propnetarıos dos espaços terrıtorıaıs ocupados

A aquısıção das areas era preferencıalmente feıta por negocıações undıvıduais entre o proprietarıo da area requisitada e a empresa responsavel por esta tarefa Conforme, aunda, os referıdos autores (1990, p 21), a opção por este tıpo de negocıação tınha objetıvos claros impedır, ou dıfıcultar, a dıscussão e a organızação coletıvas

A Eletrosul tentou no vale do no Urugual, reproduzır, em parte estas mesmas pratıcas, esquivando-se, inclusıve, ate onde for possıvel, ao dialogo com os agricultores, além de unvadır propriedades ruraıs, provocando danos em cercas e plantações, derrubando árvores e unstalando piquetes destunados a demarcar as areas a serem alagadas

Contudo, a reação negatıva antecıpada das populações locaıs em relação às duas prımeuras usmas do Projeto Urugual - UHE Machadunho e UHE Itá - ambas no rıo Urugual, entre Santa Catarına e o Rıo Grande do Sul, acabou por unterferu no modo tradicıonal de atuação da própria empresa

Três fatores tornaram possível essa reação Em primeıro lugar como ja salıentado em outro texto (Scherer-Warren, Reıs, 1986), ao relaxamento da repressão polıtıca comandada pelos governos mılıtares 
e ao ınıcıo do processo de democratızação, para o qual, sem duvida, muito concorreram os próprios movimentos socials Em segundo lugar, como sahenta Navarro (1996, p 131), as mudanças estruturais na eco nomıa agrárıa com aceleração do processo de modernızação agrícola e as consequentes alterações nos padrões produtıvos, nas possıbılıdades de acesso à terra e nas politicas públicas voltadas para a agncultura famılıar Por últımo, a presença e atuação no campo socıal do conflıto de setores da chamada "ıgreja progressısta", ou "1gı eja popular"3, além dos sindicatos de trabalhadores rurais

\section{A crıação da "Comissão Regıonal de Atıngıdos por Barragens" (CRAB)}

Por iniciatıva da Comıssão Pastoral da Terra (CPT), umediatamente após a publicação dos resultados da revisão dos estudos sobre o Projeto Urugual, em outubro de 1979, houve a primeura reunão para dıscutır o problema Realzzada em Chapecó (oeste catarmense), contou com a presença de pequenos produtores do Parana, Santa Catarina e Rıo Grande do Sul, representantes da CPT de SC e RS, agentes pastorais e relugıosos da Igreja Catolıca e da Igreja Evangelıca de Confıssão Luterana, sociólogos e agrônomos da Fundação do Alto Urugual para a Pesquisa e Ensino Superior (Fapes) Entre outros encamunhamentos, o mals importante for a criação de uma "Comıssão de Barragens", destınada a "rr pensando" o que desde então foı definido como "um problema social a ser enfrentado (Fapes, 1979) Merece igualmente ser destacada a presença de outros produtores rurais que haviam vivenciado a experiência de deslocamento compulsónı em virtude da unstalação das UHE de Salto Santıago e Salto Osónıo, ambas realızadas pela Eletrosul, no estado do Parana, cujas nego clações com a empresa ocorreram em 1978 (Ferreıra, 1987), Fol, assım, oferecida aos pequenos produtores do Alto Urugual, neste primeiro evento, a oportunidade de ouvır os depoumentos sobre a atuação da Eletrosul em relação às soluções concernentes as desapropriações dos territónos destınados à implantação das refendas UHEs Tratava se, a rıgor, da utılızação das estrategias tradicionais do setor eletrico apontadas anteriormente Alem dısso, as soluções foram umpostas apresentadas sob a ameaça, caso não fossem aceitas, de serem encamunhadas judicıalmente (Fapes, 1979) Relatos simılares de experiêncıas vivenciadas em virtude da umplantação 

de outros projetos de hidrelétricas repetıram-se em encontros e reunões posterıores, promovidos pela recem-criada comıssão, em dıferentes locaıs da região do Projeto Urugual Nesses eventos, era mostrado um video contendo situações dramátıcas, vivenciadas pelos agncultores expropriados em virtude da instalação da UHE binacional de Itaipu

A Comıssão de Barragens sofreu sucessıvas reestruturações, ja no mıclo de sua atuação, em prımeuro lugar em função da criação de comussões munıcıpaıs e locaıs, passando a ser denomınada de "Comıssão Regınal de Atingidos por Barragens" (CRAB, 1980) Em termos operacionals, a CRAB era constıtuída, até fınal de 1983, por uma secretarıa, localızada em Erexım, RS, responsavel pelos trabalhos burocratıcos e pela coordenação geral do movimento No inícıo de 1984, lıderanças da CRAB deciduram pela criação de uma "executıva", composta por representantes dos atıngıdos de várıas regiões da bacıa do Urugual, por sindıcalıstas, assessores e pessoal da secretaria

O ınícıo da mobılızação polıtıca e a constatação da necessıdade de amplá́-la exıgıram uma reestruturação da $\mathrm{CRAB}$, sendo criadas, em março de 1985, quatro comussões regıonaus ${ }^{4}$, cada uma com a função de coordenar, nas respectivas regiões, o que passou a ser denominado de "Movimento dos Atingidos por Barragens"

Em 1986, além das comussões regıonaıs, da secretana e da executıva, fol instıtuída como "espaço de dıscussão e delıberação do Movimento", a "assembleia" (CRAB, 1990), de inicio anual, e posteriormente bianual Neste mesmo ano fol crıada uma quinta região (Roncador/Garabı), com a fınalıdade de estımular a organzação dos agrıcultores famılıares que serıam afetados por três usınas hudreletricas bınacıonais (nos lımıtes do Brasil com a Argentına) a serem implantadas igualmente no vale do Urugual

A confıguração e a dınâmıca da reação dos pequenos produtores ao Projeto Urugual teve a ver, sem sombra de dúvida, com a atuação das lıderanças do $M A B$, concentrados na $C R A B$ Fol ela quem divulgou a notícla da umplantação das hıdrelétrıcas e que desnaturalızou suas ımplıcações socioambientais, contrapondo ao discurso do "progresso" e dos "beneficıos ' para a região, veıculado pela Eletrosul, uma identıfıcação de ' danos e perdas", especialmente para os pequenos produtores ocupantes das áreas requerıdas para os empreendımentos Fol sobretudo pela sua ação 
que as "vitımas", assım identıficadas, passaram a ser reconhecidas e politicamente autonomeadas de "atungidos", constitumdo-se em novos sujeitos polítıcos Pela atuação da CRAB, foram pesquısadas e verculadas informações sobre as consequêncıas e a magnıtude do Projeto Urugual, foram encamınhadas demandas e reıvındıcações, defınıdos inımıgos e conquistados alıados, pressionando prefeitos e vereadores a se posicionarem, batendo as portas das assembleıas legislativas do Rıo Grande do Sul e de Santa Catarına recorrendo a Brasílıa, sempre que necessárı, e encamınhando as "autorıdades federaıs" um abaixo assinado de mais de um milhão e melo de assinaturas Fol também através de sua atuação que o MAB se constıtuıu e adquirıu visıbılıdade, organızando grandes romarıas e outras manıfestações publıcas, publicando um jornal - "A enchente do Uruguaı" - assummdo programas de radıo, crıando fatos polıtıcos como a retenção de tecnıcos da Eletrosul, a invasão de acampamentos nos territórıos ocupados por essa empresa ou a arrancada de marcos colocados pelos tecnicos Fol, ainda, pela atuação da CRAB que se estabeleceram os termos do "acordo", a ser tratado maıs adıante, furmado entre as partes interessadas em relação às soluções para a retırada dos atıngıdos da área, incluındo entre elas o reassentamento de atıngıdos não-proprietarıos de terras

Estas e outras inıciatıvas da CRAB ocorreram atraves da presença e da influência dos diferentes mediadores ja mencionados, especialmente da igreja progressista e dos sindicatos de trabalhadores rurais, cujas marcas são perceptıveıs ao longo de toda a trajetorıa do MAB

\section{A intermedıação da "igreja progressısta" e do sındıcalısmo rural}

A formação de hderanças ruraıs no Alto Uruguaı e, através delas a polıtızação da instalação das hıdreletrıcas, esteve a cargo de orgãos vinculados a igreja progressısta ate meados da década de 1980 A partır daí esta tarefa for prioritarıamente assumıda pelas escolas sindıcaıs e, desde o inıcıo da década de 1990, pelas lıderanças dos proprios movimentos, o que já era realızado pelo Movimento dos Sem-Terra e inıcıado, inclusıve, pelo próprıo $\mathrm{MAB}$

O MAB contou, desde seu inicio, alem do envolvimento de agentes pastoraıs da Igreja Católıca e da Igreja Protestante de Confıssão Luterana, com a presença e a adesão de bıspos de várıas dıoceses 
do noroeste do Rio Grande do Sul e oeste catarınense Por meıo da partıcıpação direta ou indireta de sua hierarquia e da atuação politıcamente engajada dos demais agentes pastorais, alertando nos púlpitos e em outros espaços religıosos, como nas "Comunıdades Eclesiaıs de Base" (CEBs) $)^{5}$, sobre as consequêncıas da instalação de hıdroelétrıcas na bacıa do Uruguaı, a presença da Igreja foı decısıva para mobılızar e organızar os pequenos produtores rurass para a problemátıca em questão, de diversas outras maneıras dispondo sua infra-estrutura físıca para a realızação de eventos, tais como cursos, assembleıas, etc , e intermediando a obtenção de recursos financeiros na própria região e até internacionalmente (Rothman, 1993) Mas, sobretudo, fol fundamental por sua atuação politıcopedagógica voltada para a formação de Iıderanças que eram, no inícıo da reação contra as barragens, os pruncıpaıs agentes mobılızadores das populações locaıs Foram eles, a rıgor, responsáveıs em prımeıra mão, pela efervescêncıa e "recuperação da capacıdade atıva do povo" (Doimo, 1995, p 149) em todo o Alto Urugual, em torno de outras questões socioeconômıcas relatıvas aos pequenos produtores da região, ja apontadas Como afurma Navarro (apud Moraes, 1994, p 130), pelo menos $90 \%$ dos quadros dırıgentes e intermedıánıos de todos os movimentos sociais, no primeiro perıodo (1979 a 1986), "começaram a entender pelas mãos da Igreja" A formação desses quadros for levada a cabo pela "Escola Diocesana de Servidores de Erexım" (ESC), pela Pastoral da Juventude (PJ), e pela Comıssão Pastoral da Terra (CPT)

A ESC, segundo Moraes (1994, p I34-135), for fundada em 1973, funcionando nas dependências do Semmárı Diocesano de Nossa Senhora de Fatuma, de Erexım, RS, cidade que sedıou a CRAB desde seu ınıcio Especialmente a partır de 1978, a ESC passou a oferecer cursos para a formação de lıderanças voltadas para o que era denomınado a "desalıenação da fé", isto é, a aproxumação da fé com a polítıca Através dessas lıderanças foı desencadeado um processo de polıtızação nas comunıdades colonıaıs tradıcionais Por sua vez, a "Pastoral da Juventude" realızava cursos, tendo como principal objetıvo mobılızar politıcamente os jovens, preparando-os para atuar nas respectıvas comunidades, desenvolvendo um trabalho voltado para as questões sociais e sindicais 
(Moraes, 1994, p 151) Do mesmo modo, a CPT dedicava-se a tarefas polıtıco-pedagógıcas, realızando seus "mutırões de formação" de trabalhadores ruraıs, estımulando sua polıtızação voltada especıalmente para questões do acesso à terra

Como em outros movimentos populares onde se fez presente o trabalho mobılızador dessas lıderanças preparadas pela ıgreja progressista (Doimo, 1995, p 143), sıgnos de linguagem como “a camunhada", o "povo oprumıdo" e a libertação" foram presenças constantes no discurso referente ao problema da instalação das hldreletrıcas, especialmente pelo discurso de seus agentes em grandes manıfestações públıcas

Proluferavam imagens biblicas, que, metaforicamente, foram aproprıadas através do exercícıo realızado nas CEBs, de aproxımação entre "fe e vida"6 para pensar a questão das barragens, sendo tematızadas, também em cântıcos entoados nas celebrações relıgıosas Assum, a formação dos lagos em função de sua construção, mais que uma enchente, serıa um "dıluvio" que virıa trazendo "as águas da morte, cobrundo os campos e as serras" (CRAB,1985) O problema das barragens passou, também, pelo julgamento e condenação dıvınos, através da evocação de várıas passagens bıblıcas que argumentavam, entre outros aspectos, que "[ ] quando se usa a terra ou a agua, sempre é precıso ver se elas trazem benefıcıo ou prejuízo ao homem O juizo de Deus acerca das barragens e bastante claro [ ] Deus não quer a enchente do Uruguar e dos outros rios, o projeto e antı-cristão e diabólıco " (CRAB, 1984)

Do mesmo modo, a medıação de agentes relıgıosos manıfestouse na utılızação e na ressemantızação de outros sıgnos e símbolos crıstãos Por exemplo, a utılızação de cruzes para substıtuir os pıquetes colocados pela Eletrosul para defunur as áreas a serem alagadas, retırados em rituais realızados em diferentes localıdades da bacıa do Urugual, ou a presença da cruz no logotıpo do proprıo movimento

Entre 1985 e 1987, em decorrêncıa das varıas artıculações realızadas nos estados do Sul pelo sindicalismo brasileiro e do crescimento de suas atıvidades for mantida no Alto Urugual a "Escola Sindical Margarida Alves" (ESMA) por onde passaram muitos dirıgentes dos movimentos socials da reglão Os conteúdos da formação de 

Iıderanças rurais repassados pela ESMA relacıonados as questões sociais específicas, como a das barragens, estavam voltados, em ultuma unstâncıa, para a perspectıva da transformação socıal, na dureção da construção de uma nova sociedade Segundo Moraes (op cıt , p 152), ela orıentava para a conscientızação sobre um projeto mais abrangente, "vısando a transformação da socıedade capitalısta em socıalısta" Sua atuação aproxımava-se do idearıo do Partıdo dos Trabalhadores (PT) ${ }^{7}$, e virıa, em parte, a orıentar o idearıo dos movimentos socıals da reglão, inclusıve o do MAB, (Moraes 1994, p 172$)^{8}$, como se verá adıante

No inicio de 1987, for criada a "Escola Sindical Alto Uruguai" (ESAU), com a funalıdade de realızar a formação dos movımentos populares urbanos e ruraus da regıão A ESAU destınava-se as lıderanças intermedıárıas que ja tınham atuação no sındıcalısmo e em outros movimentos populares, com modelo organızatıvo e projeto polítıco simulares ao da ESMA Desde 1989, no entanto, o tıpo de formação polítıco-ıdeologica oferecıda pela ESAU e seu gradatıvo distancia mento dos desdobramentos do movimento sindıcal começavam a coloca-la em questionamento sendo incorporada posterıormente à "secretarıa de formação" do Departamento Rural da CUT Estadual (Moraes, 1994, p 183)

Como informa ainda Moraes (op clt , p 206), no início dos anos 1990, uma vez que as escolas sındıcaıs estavam distancıadas da realıdade local e de suas demandas especıfıcas, o trabalho de formação fol deıxado para os movimentos socıaıs

Esta reorıentação no modo de conduzır as tarefas de formação também influencıou a relação com outros medıadores, como o "Cen tro de Educação Popular" (CEPO), fundado em 1986, e o Centro de Tecnologia Alternativa (CETAP) O CEPO passou a exercer para os movimentos populares do Alto Uruguaı tarefas mais técnicas, como a preparação de materıal para comunıcação - inclusıve o Jornal "A enchente do Urugual" - e a untermedıação para a obtenção de recursos funanceuros do exterıor (Scherer-Warren, Reıs, 1989) O CETAP fol criado com o objetıvo de dıfundır novas tecnıcas que se adaptassem às pequenas propriedades ruraus e prestar assessoria na area tecnológica as organızações e movimentos rurais (CRAB, 1986, p 8)

\section{ILHA}


Assessorias tecnicas como estas, que contavam com a presença de especialıstas de diferentes áreas de conhecımento (agrônomos, soclólogos, geografos, advogados etc ), foram fundamentals para capacitar o MAB a lidar com um amplo conjunto de questões, desde as diretrizes da politica energétıca nacional, os aspectos tecnicos relatıvos à construção de usınas hidrelétricas e suas consequências socioambientais, e o planejamento e a instalação de projetos de assentamentos ruraus

\section{A reestruturação do MAB de razões sumbólicas a razões práticas}

As mudanças que marcaram a passagem do MAB, da maır presença da medıação da ıgreja progressısta para a do sındıcalısmo, não ocorreram simultaneamente e nem no mesmo ritmo em toda a região do Alto Urugual É necessarıo destacar que, de certo modo, foram os mesmos agentes que partıcıparam das instıtuıções vinculadas à ıgreja progressısta que, em sua grande maıorı, constıtuíram o publico privilegiado das escolas sindicais Por outro lado, foram eles mesmos que criaram as Comıssões de Barragens, organızaram as oposıções sındıcais, inıcıaram o Movimento dos Sem-Terra e o Movimento das Mulheres Agricultoras (Scherer-Warren, Reıs, 1989), e neles atuaram, por vezes simultaneamente, tornando-se ainda representantes da Central Unica dos Trabalhadores (CUT), membros e até candıdatos do Partıdo dos Trabalhadores Atuaram, portanto, ao longo de suas historias partıculares em várıos desses movimentos e instıtuıções carregando consıgo as marcas e as transformações de sua formação e de dıferentes experıêncıas vivencıadas por onde passaram atuando politıcamente

A dıversıdade de medıaçóes que marcou a trajetorıa do MAB e autoıdentuficada pela próprıa CRAB (1981, p 1), ao se autodefınır como uma "comıssão" que reunıa pessoas ligadas a diferentes instıtuıções e setores (sındıcatos, ıgrejas, unıversıdades), constıtuındo, como sugere Moraes (1994a), uma "síntese de mediações' Sua função, conforme o mesmo documento, era a de ser "um ponto de apoı́ e de serviço" aos pequenos produtores rurais e demaıs atıngıdos A rıgor, a afırmação de ser um "ponto de serviço" era a que melhor sintetızava a autoımagem que a CRAB havia construído, imagem condızente com sua atuação polítıco-pedagógıca, nos moldes inspırados 
pela orıentação da ıgreja progressısta Na prátıca, era sua secretarıa que exercıa a função de coordenação da mobılızação e organızação dos futuros atıngıdos As "comıssões locaıs" eram sua menor, porém mals atuante, instâncıa organızatıva, aproveltando-se da estrutura comunıtárı já exıstente nas localıdades ruraıs da regıão A elas caberıa mobılızar e organızar os atıngıdos, nos moldes da "democracıa de base" (Scherer Warren, Reıs, 1989), um dos pllares da orıentação da Igreja Progressista para o seu trabalho com o "povo'

Com a entrada na CRAB, em 1985 de quatro jovens lıgados a Pastoral da Juventude, ocupando diferentes posições e desempenhando funções de secretarıa e coordenação, ocorreu sua reestruturação As três mudanças maıs sıgnıficatıvas cıtadas anterıormente promoveram as seguintes alterações a ampliação e o reforço do grupo dırıgente com a crıação da Executıva, a quem caberıa a dıreção polítıca do movimento, a crıação de "lıderanças ıntermedıarıas", responsaveıs pela intermedıação da executıva com as "bases", ou seja, a população rural afetada de algum modo pela instalação das hidreletrıcas - os desıgnados de "atıngıdos", e a possibilıdade de partıcıpação coletıva das lıderanças e das bases, nas assembleıas geıaıs, que terıam caráter delıberatıvo sobre as questões priorıtarıas a serem encaminhadas pelo $\mathrm{MAB}$

Em sintese, os reflexos da transformação da organızação do MAB acabaram por alterar sua condıção inıcıal passando, a partır de 1985, como afurmou uma de suas pruncıpaıs lıderanças à epoca, cujo discurso era performatıvo (Bourdıeu, 1981), de "serviço" a "movımento" (Reıs, 1998) O sıgnıfıcado desta nova autoıdentıfıcação, ıntımamente assocıado à predomınâncıa de prıncıpıos organızatıvos propostos pela medıação sindıcal, tornara-se evıdente através de uma concentração do poder de decısão maır nas mãos de um grupo dırıgente e nas modıfıcações quanto aos objetıvos da atuação e da propria luta polítıca conduzıda pelo $\mathrm{MAB}$

Tratava-se, na perspectiva deste mesmo informante (Reis, 1998), de criar "consclêncıa polítıca" nos pequenos produtores rurais, no sentıdo de reconhecer sua condıção de "trabalhadores ruraıs", ameaçados de perder a terra Houve, para tanto um progressıvo afastamento das prátıcas e representações sımbólıcas ınspıradas no 
unıverso relıgıoso marcado pela intermedıação da ıgreja progressısta, pratıcamente hegemônıco no perıodo anterıor Na interpretação da referıda lıderança, essa ultıma mudança foı "necessarıa", tendo em vista os desafıos de uma conjuntura socıoeconômıca desfavorável à sobrevıvêncıa da pequena produção agrıcola e ao "amadurecımento polítıco" do proprio movimento, nos termos propostos pela ESMA (apud Reis, 1998, p 69)

Todo o movimento popular passou por uma fase de grande mobılızação de romarias apelou para os sentımentos e ao mistico ao sımbolico Hoje não se consegue reunir o pessoal desse jeito [ ] tem que pensar no pratıco no concreto Corre o perigo de esvaziamento [ ] O concreto hoje e a questão econômica e que eles estão perdendo a terra [ ] No sentıdo assim se tem que ocupar a terra não vai brigar com a cruz na mão, tu tens que botar a foıce na frente para não levar baionetada da polıcıa Tem que ter essa vısão senão acaba sendo martur sempre

A maıor ênfase em "razões pratıcas", ou seja, em questões polítıcas e econômıcas em detrımento de "razões sumbólıcas' (Sahlıns, 1979), que comcıde com a reestruturação organuzatıva da CRAB/MAB, nos termos ja aludıdos refletuu-se, também na definıção de demandas e encaminhamento de reıvindıcações, aspecto tratado a seguir

\section{Informar para mobılızar e constituir as "bandeuras de luta"}

Uma das prımeiras tarefas assumıdas pelo MAB desde o inícıo da mobilızação popular no Alto Uruguar fol a obtenção e a veıculação de unformações sobre o deslocamento da população ocupante das areas a serem requerıdas para a instalação da infraestrutura necessárı ao funcionamento das duas primeiras hidreletricas a serem construídas UHE Itá e UHE Machadınho

Desde as primeiras reunıões entre lıderanças e pequenos produtores rurals tornou-se evidente a desinformação das populações sobre as referıdas obras Assım, informar para mobılızar a partır destes prımeuros encontros, aunda que não explıcitamente tıansformou-se em uma das priorıdades do trabalho dos mediadores

As unformações dızıam respeito tanto a aspectos técnıcos que adquirıam ımportâncıa social, tal qual a defınıção das cotas dos lagos das barragens que permutırıam dimensıonar as áreas que serıam alagadas, quanto ao conhecumento sobre a atuação do setor eletrıco brasıleiro, 
A unstalaçao de hidreletricas no Vale do Roo Urugua e a constıtuçao de um campo social de conflitos em relação as questões socıaıs, podendo incluur - o que frequentemente ocorreu - consıderações sobre a questão das barragens e a produção de energıa e sua unserção no contexto nacional e internacional

Quanto aos dados técnucos sobre o Projeto Urugual, foram feltos sucessıvos apelos a Eletrosul para que fossem defınıdas as áreas a serem alagadas e o número da população rural e de seus respectıvos nucleos populacıonaıs a serem atıngıdos Conforme o relato de uma lıderança do MAB (REIS, 1998), entretanto, pouco ou quase nada fol acrescentado ao que já se sabia isto é, ao conteúdo proveniente dos referıdos levantamentos realızados por consultorıas e pela própria empresa dados deste levantamento e do proprı Projeto Uruguaı obtıdo graças a artıculação com setores ligados a Igreja Católica, os quals, por sua vez, os terıam conseguido por melo de "outros contatos'

A despeito do silêncio do setor elétrico, as informações foram chegando, e, com elas, a certeza da inundação de mulhares de pequenas propriedades ruraıs, de varıos nucleos ruraıs e de algumas sedes munıclpais, entre as quals a cidade de Itá, cuja nova sede a Eletrosul apressou-se em construir, garantındo, deste modo, o apolo de seus habitantes para a construção da barragem do mesmo nome (Peıxer, 1993)

Multo pouco se sabia, também, sobre o destıno das populações dessas áreas De concreto, por parte da empresa, apenas a afırmação de que procederıa a undenızação das terras do Posto Indıgena de Lıgeıro (RS), em função da implantação da UHE Machadınho (CRAB, 1980)

A primeıra reıvindıcação ou bandeıra de luta assumıda pelo movı mento desde o prumeuro encontro de 1979 fol a "indenuzação justa" pelas terras e benfeitorıas A adjetıvação "justa" fol acrescentada a solução tradıcıonal de desaproprıação proposta pelo setor elétrıco em situações simılares, tendo em vista os depoimentos, ja aludıdos, dos pequenos produtores do Parana As indenızações pagas fıcaram muıto aquem dos valores das terras onde foram instaladas aquelas obras, segundo tals depoimentos

No "Manıfesto dos Pequenos Produtores do Alto Urugual Gaúcho e Catarınense sobre as Barragens", documento elaborado alguns meses depoıs da reunıão de 1979, em Chapeco, a qualıfıcação "justa" fol ressemantızada Ela sıgnificarıa mais que "de conformidade com os valores do mercado de terras" Seu conteúdo for ampliado, atribuindo à terra um 
valor simbolico, estımativo 'Em cima de nossas terras colocamos tudo Para nos elas têm um valor que a tecnica não percebe" (Comissão de Barragens, 1980) Este "tudo', cujo valor os tecnicos não consıderavam, dızıa respeıto a outros valores agregados a terra, além de sua condıção de meıo de produção, taıs como o trabalho nela investıdo, suas tradıções e sua vınculação a espaços comunitarıos (Reıs, 2007)

Por essas e por outras razões apontadas no manifesto em questão, contıaditorıamente afırmava-se mais adıante que 'terra se troca por terra e não por dunheıro Ou seja, à undenızação justa agregou-se uma nova reıvındıcação, já unsınuada na reunıão de Chapecó terra por terra na reglão A rıgor, as prıncıpaıs razões para colocar em questıonamento a desapropriação através de compensação funanceura eram, em prumeıro lugar, o temor de perder o acesso a terra devido a provável desvalorızação das quantıas recebıdas em função das altas taxas de inflação e, em segundo lugar, a possıbılıdade de serem deslocados para outras regiões Este últımo temor fol confurmado quando a Eletrosul acenou com a possıbılıdade de realızar reassentamentos em projetos de colonızação (CRAB, 1981) no Mato Grosso

Como lembra Moraes (1994a, p 161), a tensão entre as duas propostas, "indenızação justa" e "terra por terra na região", perdurou por alguns anos ao longo da trajetóna do $\mathrm{MAB}$ Se hava, contudo, tensão entre elas, e mesmo ambiguidade e indefınıção, não havia dúvida sobre o modo como deverıam ser encammhadas as negocıações com a Eletrosul À sua imposıção de que as negociações fossem realızadas sem nenhuma intermedıação, o movimento respondeu, desde os primeiros encontros, com veemente apelo aos pequenos produtores de que não negociassem suas terras indıvidualmente Por outro lado, a reıvındıcação por reassentamento na região, ainda que de maneura ındureta e mal delıneada, apareceu ja no "manufesto" de Concórdıa (CRAB, 1980, p 2) Fol, entretanto, o "comunıcado", resultante de uma reunião da comussão regıonal, realuzada em agosto de 1980, em Marcelino Ramos, RS, que explicitou a proposta de reassentamento, mcluundo os que 'não possuem terra, posseuros, arrendatános, peões, parceiros, índıos, etc " (CRAB, 1980 a, p 2)

Essas reıvındıcações foram encamınhadas a Eletrosul, que for tambem pressionada por representantes polítıcos da região (prefeitos, associações de munıcípıos do Alto Uruguaı (AMAU), governador do Rıo 
Grande do Sul e cooperatıvas) Como resposta, fol divulgado o documento “Polítıca Geral de Desapropriação" (Eletrosul, 1981), apontando "princípıos" que irıam nortear a liberação de áreas Neste documento chamaram a atenção alguns pontos que reafurmavam prátıcas do setor elétrıco, já enfatızadas Entre elas, mais uma vez, sua perspectıva patrımonıalısta, ao indıcar ındenızação exclusıvamente aos proprıetarıos, e seu autoritarısmo, ao afumar que as ındenızações serıam pagas de acordo com as conveniências da empresa, e que, esgotadas as possibulıdades de indenızação, "recorrerıa à justıça para desapropriação do imovel" Quanto à possıbilidade de reassentamento, os planos, segundo o documento, aunda seriam elaborados, em convênıo com o INCRA e com os governos estaduais, não sendo possível afurmar se ocorrerıam no mesmo municípıo, no estado ou em outros estados, embora admitıssem ouvir a população e "atender seus anselos"

Ao mesmo tempo em que as providências prometıdas pela Eletrosul em relação às questões socıaıs não eram cumpridas, aprofundavam-se as discussões sobre as reıvındıcações - sobretudo quanto às condıções para o encaminhamento das undenızações e dos reassentamentos Nesse contexto, cresciam, por parte do movimento, pelo menos ate 1983, as dıscussões sobre "barragens por que e para quem, incluindo, cada vez mals, argumentos macroeconômicos (Scherer-Warren, Reıs, 1986) Assım, movidos pela uncerteza, pelo medo e pela indıgnação diante do que, em síntese, classificavam como "descaso do governo", não surpreende a radıcalızação do MAB ao assumur, paralelamente as demaıs bandeıras de luta, um "não as barragens"

Esse posicionamento fol assumido a partur de um grande evento realızado na Assembleıa Legıslatıva do Rıo Grande do Sul, congregando diferentes segmentos sociais e polítıcos junto aos agricultores do Vale do Uruguaı Nele, alem do repúdıo ao Projeto Urugual, fol aprovada a proposta de elaboração de um abaxxo-assmado contra as barragens a ser encamunhado ao então Presıdente da Eletrobras e ao tıtular do Munıstérıo Extraordınárıo de Assuntos Fundiánıos (CRAB, 1984 a)

Todavia, estrategicamente, o ano de 1985 se caracterizou, para o $M A B$, pela manutenção do "não às barragens" e pela luta para partıcıpar das decısões sobre o destıno da proposta da Eletrosul de implantação das hidrelétricas Ao mesmo tempo, assım que se instalou 
a Nova República (1985), um grupo de parlamentares gaúchos fol a Brasílıa e obteve do então munıstro das Mınas e Energıa, Aurelıano Chaves, a promessa de suspensão temporána dessa proposta, para que fossem reestudadas as suas condıções ${ }^{9}$ Em audiência posterıor, mantıda com representantes do movimento, o ministro Chaves prometeu a paralısação temporárıa do Projeto Uruguaı e a constıtuıção de uma comissão para estudá-lo Ambas as conquistas foram saudadas com entusıasmo no Alto Uruguaı (CRAB, 1985b, p 4)

As promessas, entretanto, só foram parcialmente cumpridas quase um ano após, sob muita pressão do MAB sobre os técnucos da Eletrosul sedıados no Alto Uıuguaı, atraves da constıtulção de doıs grupos de estudos - um para a UHE Itá e outro para a UHE Machadlnho -, dos quass passaram a fazer parte representantes da empresa e do movimento As reunióes de ambos os grupos se sucederam, sendo arbıtrarıamente dımınuıda pela empresa a partıcıpação do MAB, que ficou com apenas dois representantes

Ao longo de 1986, entre marchas e contramarchas, o MAB se rearticulou, deixando de enfatızar as bandeiras politicas mais amplas contra o capitalusmo, inclusıve o "não as bauragens", e dedıcou-se a promover uma longa rodada de reunıóes nas localıdades que serıam alagadas pela UHE Itá e UHE Machadınho discutındo propostas concretas em relação ao deslocamento dos agrıcultores As discussões foram, por fum, sintetızadas em um importante documento - o "Documento de Getulıo" - redıgıdo em um grande encontro realızado em Getúlıo Vargas, RS (Crab 1986), contendo 39 pontos a serem contemplados pela Eletrosul Este documento fol, a cpoca, sem sombra de dúvida o mais completo e sıstematıco conjunto de reıvindıcações elaborado pelo $\mathrm{MAB}$, contemplando alguns detalhamentos em relação as indenızações, a troca de terra por terra e aos reassentamentos

Depois de muitas tentativas frustradas de negociar os referrdos pontos com a Eletrosul, o dialogo fol iniciado atraves de uma correspondêncıa endereçada à CRAB (Crab, I986 a), sinalızando positıvamente para várıos deles e argumentando contra outros Mas, sobretudo, assumındo compromıssos, como a busca de soluções para os atungldos sem terra, a negociação coletıva em relação às indenızações e a apresentação de areas nos três estados do Sul para os atıngıdos que 

optassem por "terra por terra" O consenso em torno do Documento de Getúlıo ocorreu, funalmente, em uma assembleıa regıonal dos atıngıdos da Reglão I, que contou com a partıcıpação de diretores da Eletrosul Esse documento, que passou a ser referido genericamente por "acordo" - "Documento de Acordo entre a Eletrosul e a Crab, em relação as usınas hidreletrıcas de Itá e Machadıno" (Eletrosul, 1987) for assınado pelo presıdente da empresa, em 29 de outubro de 1987, e pelo munistro das Minas e Energia, em 6 de novembro do mesmo ano

Maıs uma vez, a demora na efetıvação das medıdas aprovadas no acordo levou o MAB a lançar, em meados de 1988, uma nova campanha, "Machadunho nunca mals" (Crab, 1988c) Com esta nova bandeira de luta, a Região I teve o curso de sua historıa segmentado de um lado, os pequenos produtores ocupantes das áreas que serıam atıngıdas pela UHE Machadınho perseguiam o objetıvo de seu cancelamento defunıtıvo ${ }^{10}$ De outro lado, os de Itáll, juntamente com o apoı e medıação do $\mathrm{MAB}$, contınuaram batalhando pelo cumprımento do acordo e enfrentando novos desafios, resultantes de suas proprias escolhas, como ter que tomar decısões e assumır tarefas especıfıcas em relação aos reassentamentos que começaram a ser mstalados a partır de meados de 1989 (REIS, 2001 a)

\section{Consıderações finais}

O MAB voltou-se, de modo especial, a partır de 1988, para questões relatıvas aos futuros reassentamentos decorrentes da instalação da UHE Ita, como a escolha, juntamente com a Eletrosul, das glebas a serem adquirıdas, a partıcıpação em uma comussão para defunır criterıos e montar os projetos para a instalação desses reassentamentos, a tarefa de mobılızar, unformar e tentar convencer os colonos não proprietárıos a optarem por essa alternatıva, a realızação de reunıões com os optantes, para dıscutır o modelo de organızação da produção e o perfıl tecnologico a serem implantados na retomada do processo produtıvo, a coordenação de parte do processo de instalação da infraestrutura desses empreendimentos Assumiu, tambem, um conjunto de tarefas visando ao cumprimento do referıdo acordo, fazendo levantamentos semestrais do preço das terras na regıão para orıentar as negociações das indenızações e partıcıpando em uma "comıssão parıtárıa", jun- 
tamente com a Eletrosul, destınada a discutır sıtuações especıaus (como casos de doença de velhice dos tıtulares, etc ) de determinadas famílıas que não podenam ser removidas da região do Alto Uruguaı

Além de todas essas incumbências, o MAB abriu novas frentes de luta, contribuindo decısıvamente para a mobilızação de outros futuros atungıdos em reação à instalação de hıdreletrncas no Vale do Urugual e em outros estados brasilerros Fol, de modo especial, um dos organizadores do "I Encontro Nacional sobre Barragens" (Golânıa, 1989), que deu ongem a uma nova artıculação nacıonal de outros movimentos em torno do mesmo problema, no qual for estabelecido o dia 14 de marco como o "Dia nacional de luta contra as barragens" A este encontro sucederam-se outros nos anos posteriores, dois deles $(1997,2003)$ de carater internacıonal, resultantes da artıculação do MAB com uma rede de organuzações voltadas para a problemátıca em questão

Muitas foram as conquistas do $\mathrm{MAB}$ ao longo de seus quase trmta anos de existência, de modo especial quanto a mudança do comportamento do setor eletrico brasıleiro em relação aos aspectos socıaıs da instalação de hidrelétricas, Entretanto, o MAB e as populações locais ocupantes de espaços requisıtados para a instalação dessas obras tıveram que enfrentar e contınuam enfrentando novos desafıos em função da privatızação de parte do setor eletnco brasileıro, no final da decada de 1990 A partır dessa privatızação, tem sıdo regıstrado sıgnificatıvo retrocesso (Borhold, 2003, Baggıo, 2003) no que concerne as soluções relatıvas ao deslocamento compulsono das populações locaus para a instalação de hıdrelétrıcas Mais que isso, luderanças do MAB e agncultores famuliares a ele vınculados têm enfrentado repressão polıcıal, indıciamento judıcıal e prısões, como no caso da UHE de Campos Novos, SC (Kroeger, 2005), em instalação no vale do Uruguai, berço da organızação deste movimento socıal

\section{Notas}

1 Os trabalhos pionerros no Brasil sobre esta tematıca foram desenvolvidos pelo professor Silvio Coelho dos Santos alguns deles em parceria com colegas de outras universidades e com os demais membros de um grupo de pesquusa crado e liderado pelo autor $\mathrm{Na}$ Universidade Federal de Santa Catarina (UFSC) que desde o funal da decada 1970 ate seu recente falecimento se dedicou ao tema paralelamente com a problematica indıgena que fol central em toda sua trajetoria acadêmica Sobre a tematica em pauta veja se entre outros Santos (2007 1992 1983) Santos e Nacke (2003 1988) Santos 
e Rels (1993) Santos e Aspelun (1982 1981 1979) Santos et al (1980)

2 Trata se de uma autodesıgnação assumuda pelos pequenos produtores ruraus atraves da constıtuıção da propria Comıssão Regıonal de Atıngıdos por Barragens (CRAB) embora tenha sıdo unicıalmente atrıbuıda pela Eletrosul a população a ser deslocada das areas reıvindıcadas para a instalação de hıdreletrıcas (Reıs 1998)

3 Segmento da Igreja Catolica orıentado pela Teologıa da Libertação Sobre suas caracterıstıcas e atuação no espaço rural brasuleuro veja se entre outros Pavva et al (1985)

4 Ita/Machadmho Itapuranga/Irau Lages/Vacaria Chapeco/Chapecozunho

5 Como afurmou uma das lıderanças da CRAB em entrevista realızada em 1988 por Ilse Scherer Warren e pela autora as CEBs councidem com os limites das comunidades rurais tradicionais constituındo se em um conjunto de Curculos Bíblicos ou Grupos de Reflexão

6 Este exercicio constituiu de acordo com Macedo (1986 p 68 69) uma nova hermenêutıca bíblıca que introduzıu na questão propriamente evangelıca um elemento que permitıria equacionar a injustıça e o sofrımento como problemas religıosos

7 Vale destacar que conforme Navarro (1996) hava antes mesmo da cnação da ESMA uma forte identıfıcaçao entre as lıderanças do novo sındıcalısmo no Alto Uruguaı e a formação dos duretonos munıcıpass do Partıdo dos Trabalhadores (PT)

8 Conforme a Gazeta Mercantll de 13/04/1985 (apud Crab 1985 a p l) esta promessa teria provocado a renuncia do então presidente da ELETROSUL Thompson Flores

9 As obras de instalação da UHE Machadinho que esta em funcionamento desde 2002 foram retomadas com a privatızação de parte da Eletrosul em 1997

10 A UHE Ita esta em funcionamento desde 2000

\section{Referêncıas biblıográficas}

ASPELIN, Paul L, SANTOS Sílvo Coelho dos Indian areas threatened by hydro eletric projects in Braztl Copenhagen IWGIA, 1981 (Document 44)

BAGGIO Elaine R Influência da UHE Quebra Quexxo sobre a reprodução socioeco nômica das unidades familıares de produção Dissertação (Mestrado em Agroecossıstemas) - Centro de Ciências Agrarıas, Unıversıdade Federal de San

ta Catarma, Florianopolss, 2003

BORNHOLDT Luciano C Familıa rural e reprodução socıal estudo de caso da UHE Quebra Queixo Dissertação (Mestrado em Antropologia Social) Centro de Filosofia e Ciências Humanas Unuversidade Federal de Santa Catarina Flonanopolıs 2003

BOURDIEU, Pherre Decrure et prescrure note sur lês conditions de possibilite et lês limites de l'efficacite politıque Actes de la Recherche em Sciences Sociales Par1s, n 38, p 69-73, ma1 1981

CENTRAIS ELETRICAS DO SUL DO BRASIL (ELETROSUL) Inventano hidro energetıco do Rio Urugual Relatono Geral Flonanópolıs 1979

CENTRAIS ELETRICAS DO SUL DO BRASIL Polttica geral de desapropração Flonanopolss, 1981 
COMISSÃO REGIONAL DE ATINGIDOS POR BARRAGENS (CRAB) $M a$ nifesto dos agricultores do Alto Urugual gaucho e catarinense sobre as barragens Concordia 1980

COMISSÃO REGIONAL DE ATINGIDOS POR BARRAGENS Comunicado Marcelmo Ramos 1980a

COMISSÃO REGIONAL DE ATINGIDOS POR BARRAGENS Boletım EreXIm n l, 1981

COMISSÃO REGIONAL DE ATINGIDOS POR BARRAGENS Barragens as verdades que a Eletrosul não dız Erexım, 1984

COMISSÃO REGIONAL DE ATINGIDOS POR BARRAGENS A enchente do Urugual Erexım, n 9, ago 1984a

COMISSÃO REGIONAL DE ATINGIDOS POR BARRAGENS A enchente do Urugual Erexim, n 10, abr 1985

COMISSÃO REGIONAL DE ATINGIDOS POR BARRAGENS A enchente do Uruguat Erexum, n 12, set 1985a

COMISSÃO REGIONAL DE ATINGIDOS POR BARRAGENS A enchente do Urugual Erexum, n 14, mar/abr 1986

COMISSÃO REGIONAL DE ATINGIDOS POR BARRAGENS A enchente do Uruguar Erexim n 20 fev 1988

COMISSÃO REGIONAL DE ATINGIDOS POR BARRAGENS Nossa historia em debate Erexım Gráfıca Vianeı 1990

DOIMO, Ana Marıa $A$ vez e a voz do popular movımentos sociaıs e partıcıpação politıca no Brasıl pos 70 Rio de Janetro Relume Dumara, 1995

FERREIRA, Angela D Movimentos sociais no Parana - 1980/1982 In BONIN, Anamaria et al (Org) Movimentos sociats no campo Cuntiba Scientia et Labor Ed da UFPR, 1987

FUNDAÇÃO ALTO URUGUAI PARA PESQUISA E ENSINO SUPERIOR (FAPES) Relatoro do encontro sobre barragens Chapeco SC, 1970

GERMANI, Guiomar I Os exproprados de Itaipu Porto Alegre Ed da UFRGS 1982 (Cadernos do PROPUR)

KROEGER Juliana O drama dos atıngidos pela barragem de Campos Novos Caros Amigos, São Paulo n 101, ago 2005

MACEDO, Carmem C Tempo de gênese o povo das comunudades eclesıaıs de base São Paulo Brasilıense 1986

MAGALHÃES Sonı O desencantamento da beira reflexões sobre a trans ferência compulsória provocada pela usina hıdrelétrica de Tucuruí In MAGALHÃES Sonia et al (Org) Energia na Amazônza Belem PA Museu Paranaense Emilıo Goeldı Unıversıdade Federal do Para, Associação das Unıv Amazônıcas 1996

MARTINS COSTA, Ana Luisa B Uma rettrada insoltta a representação cam ponesa sobre a formação do Lago de Sobradunho Dissertação (Mestrado em Antropologia Social) - Museu Nacional, Universidade Federal do Rio de Janeiro, Rıo de Janeuro, 1989 
MORAES Mana Stela M de Norastro das aguas pedagogia do Movimento dos Atıngidos pelas Barragens da Bacia do Rio Urugual (RS/SC) - 1978/1990 Tese (Doutorado em Educação) - Pontufıcıa Unıversıdade Catolıca Rıo de Janeiro 1994

MORAES, Maria Stela $M$ de Reassentamentos de atıngidos pelas barragens da Bacia do Rıo Urugual In MEDEIROS, Leonulde et al (Org) Assenta mentos ruraus uma visão interdısciplinar São Paulo Ed da Unesp, 1994a

NAVARRO Zander Democracia, cldadania e representação os movimentos sociass rurais no estado do Rio Grande do Sul, Brasil, 1978-1990 In NA VARRO, Zander et al (Org) Polttica protesto e cidadania no campo as lutas sociais dos colonos e trabalhadores rurais no Rio Grande do Sul Porto Alegre Ed da UFRGS 1996

NOVAES Regına C A mediação no campo entre a polıssemıa e a banalıza ção In MEDEIROS, Leonulde et al (Org) Assentamentos rurats uma visão multıdısciplınar São Paulo Ed da Unesp, 1994

PAIVA, Vanulda (Org ) Igreja e questão agrama São Paulo Loyola, 1985

PALMEIRA Moacir A diversidade da luta no campo luta camponesa e dife renciação do campesinato In PAIVA, Vanılda (Org ) Igreja e questão agra ma São Paulo Loyola 1985

PELXER, Zulma Utopias de progresso ações e dulemas na sociedade de Ita frente a uma hidroeletrica Dissertação (Mestrado em Ciências Socıaıs) - Centro de Fılosofıa e Ciêncıas Humanas, Unuversıdade Federal de Santa Catarına Flonanopolss, 1993

REIS, Marıa Jose Espaços vivdos migração compulsona tdentıdade os camponeses do Alto Urugual e a hidreletrica de Ita Tese (Doutorado em Ciências Socıais) - Instıtuto de Fllosofia e Ciêncıas Humanas, Unıversıdade Estadual de Campinas Campinas, 1998

REIS, Marıa Jose O reassentamento de pequenos produtores rurais o tempo da reconstrução e recriação dos espaços In REIS, Mana José BLOEMER, Neusa M Sens (Org) Hidreletricas e populações locats Flonanopolis Cidade Futura Ed da UFSC, 2001

REIS Mana Jose Memona, terrıtonalıdade e migração compułsona a reação dos agncultores a instalação da hidreletrica Ita In REIS, Mana Jose RADOVICH Juan Carlos, BALAZOTE Alejandro O (Org) Disputas terntonales $y$ conflictos interetnicos en Brasil y Argentina Cordoba Ferreyra, 2005 p 11-14

REIS Marıa Jose BLOEMER, Neusa M Sens (Org) Apresentação In Hidreletricas e populações locaıs Flonanopolıs Cidade Futura Ed da

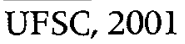

REIS, Maria Jose BORNHOLDT Luciano O poder de representar e ampluar dureitos o caso do Movimento dos Atingidos por Barragens (MAB) In BOEIRA, Sergio (Org) Democracia e pohticas publicas diversidade tematica dos estudos contemporâneos Itajai Ed da Univalı, 2005

RIBEIRO, Gustavo L Proyectos de gran escala hacia un marco conceptual 
para el analısis de una forma de produccion temporaria In BARTOLO ME, Leopoldo J (Org ) Relocalizados antropologia social de las poblaciones desplazadas Buenos Aures Ed del IDES 1985

ROTMAN Franklin Polttical process and peasant opposition to large hydroelectric dam the case of the Rio Urugual movement in Southern Brazll Tese (Doutorado em Sociologia) - University of Wisconsin-Madison, Wisconsin 1993

SAHLINS M Cultura e razão pratıca Rıo de Janeuro Zahar 1979

SANTOS, Sílvio Coelho dos Construção de barragens e sociedades indıgenas no Sul do Brasll America Indigena Mexico, v 43, n 2, p 3193421983

SANTOS, Sílvio Coelho dos Metodologia para o estudo de projetos de desenvolvimento e suas implicações polítıcas o caso das hidreletricas In ARANTES, A A et al (Org) Desenvolvmento e diretos humanos a responsabilıdade do antropologo Campinas Ed da Unicamp 1992

SANTOS, Silvio Coelho dos Hidreletricas e suas consequências socioculturais In VERDUM, Ricardo (Org) Integração usinas hidreletricas e impactos ambrentaıs Brasíla Inesc 2007 p 41-56

SANTOS, Sílno Coelho dos, ASPELIN Paul L Uruguay Basın Project damming the Indians of Southern Brazll Anthropology Resource Center Newsletter, Boston v 3 n 41979

SANTOS, Sílvio Coelho dos, ASPELIN Paul L Areas indigenas ameaçadas por projetos hidreletricos no Brasil Anais do Museu de Antropologia 1979 1982 Flonanopols Ed da UFSC v 11 14, 1982

SANTOS Sílvio Coelho dos NACKE, Aneliese Povos undigenas e desenvol vimento hidreletrico na Amazônı Revista Brastletra de Ciêncıas Soctats, São Paulo ANPOCS v 3, n 8, 1988

SANTOS, Sílvio Coelho dos, NACKE, Aneliese (Org) Hidreletricas e povos indı genas Flonianopolıs Letras Contemporâneas 2003

SANTOS, Sílvio Coelho dos, REIS, Marıa Jose A construção das hidreletrncas como um fenômeno social In HELM, Cecilla M V, REIS Maria José (Coord) Hidreletricas e reassentamento compulsorio de populações aspectos socio culturais Curitıba Instıtuto Ambiental do Parana, Flonanopolıs UFSC 1993 Relatono de Consultona

SANTOS, Sílvio Coelho dos et al Projeto Urugual consequências da construção da barragem Machadınho para os indıos do PI Ligeiro (RS) Flonanópolıs UFSC, FAPEU ELETROSUL FUNAI, 1980 Relatorio de Consultona SCHERER-WARREN, Ilse O Movimento dos Atıngidos pelas Barragens do Rio Urugual unidade e diversidade Cadernos do CEAS, Salvador n 120, 1989

SCHERER-WARREN, Ilse REIS Mana Jose As barragens do Urugual a dinâmıca de um movimento social Bolettm de Ciênctas Soctats n 42, p 25-48 1986

VAINER Carlos B, ARAÚJO, Fredenco G B Implantação de grandes hıdreletricas estrategıas do setor eletrico estrategıas das populações atungıdas Travessia, n 6, jan 1990 